\author{
https://doi.org/10.52449/1857-4114.2020.35-1.10
}

CZU: 796.012:796.333

\title{
CURRENT CONCEPTS ON THE DEVELOPMENT OF THE FORCE-SPEED CAPACITY OF PERFORMANCE RUGBY PLAYERS
}

\author{
Tăbîrța Vasile \\ ${ }^{1}$ State University of Physical Education and sport, Chişinău, Republic of Moldova
}

\begin{abstract}
In this article is addressed the current issue on the development of force-speed capacity in the game of rugby. The main condition for practicing performance rugby is force-speed training. Muscle increases as a result of high intensity efforts, while volume-based efforts have insignificant effects. Some sports training specialists consider that the development of combined force-speed motor qualities is one of the most important aspects of training and covers all segments. The training of players for competition, through the specific complexity of sports games, is another factor that favors the increase of the training efficiency. Within a group, a team, the interrelationships between the individuals are not always synergistically coordinated, which amplifies the complexity of the training. The periodization of the training and the planning of the effort within it will take into account the organizational realities of the training and the competition system, aiming to achieve maximum performance in accordance with the objectives proposed.
\end{abstract}

Keywords: senior rugby players, force-speed, performance, motor training, position of play.

Among all the motor qualities, the strength-speed ability is an absolutely necessary one to achieve high results in the game of rugby. Given that field trips play a decisive role in the optimal resolution of technical and tactical tasks in rugby, exercise structures should aim at developing strengthspeed resistance, in particular the lower limbs $[1,2,5,6,7]$. The main means of specific physical training are the competition exercises, which are the subject of competition in the respective sports branch, as well as the special training exercises to be developed on the basis of the former.

Some specialists $[1,2,6,7,8]$, agree that during the weekly training cycle within the competition period there should be no shortage of lessons in the development of general and special strength-to-speed and resistance.

V.N. Platonov [6, p. 152] outlines a principle that the body can usually achieve an unlimited capacity for mobilization, necessary in a competition, if a training programme has been carried out in advance which has incurred a sufficient variation volume in relation to the efforts.

The main condition for practicing performance sport is force-speed training. Muscle increases as a result of high intensity efforts, while volume-based efforts have insignificant effects $[1,2,3,4,5,8]$. The orientation towards increasing muscle strength has a considerable influence on the structure of muscle tissue, creating the prerequisites for the formation of a muscle adapted in this direction, from childhood age. So performing force training in the context of this age requires compliance with methodical rules (weights, fixed scale exercises, hangings, swings, jumping, breathing and correction exercises), etc.

Acording to A. Dragnea [5, p.101] in organizing and directing sports training, must be it taken account of the premises of performance as well as the structure of performance capacity, with their mutual 
relations, which implies a correct diagnosis of the possibilities of the individual and the conditions for their development. The diagnosis of skills is not only a finding of a state in the development of the individual, it must be correlated with the peculiarities of the chronological and biological age, when the processes of growth and development are carried out according to certain strict standarts.

According to T. Bompa [5, p.124], athletes should be concerned with the development of force during all years of training, even if it is not necessary to thicken the muscles.

Maximum force training creates the conditional basis for explosive force training. The similarities between the two types of force are so great that to improve the explosive force are often applied methods of maximum force training. The two types of force have strong connections in terms of nerve activation, which can be the basis of the ability to transfer from maximum force to explosive.

Muscle strength allows the development of tension in a maximum contraction $[1,2,6$, 7] is proportional to the acceleration it causes. The greater the force that acts on the body, the greater the acceleration, but this relationship operates and vice versa, the increased speed of a movement leads to increased force.

In this respect we can say that the force determines the speed of the movements, the speed of movement of the player, the intensity with which the ball is transmitted, the player's commitment to the fight for the ball.

As regards the basic preparation period, the aerobic and anaerobic effort should not be mixed. During the competition period, specific physical training will be carried out both with non-specific means and with specific means in an appropriate proportion.

The strength of the muscle through training can also be increased by the use of their elasticity. Some authors recommend acceleration-braking exercises that help improve muscle elasticity. The use, in the case of acceleration-braking exercises of some difficulties, even insignificant, leads to an increase in the moment of inertia. This intensifies the contractions of the muscles, not only to overcome the resting inertia of the mass of the apparatus, but also to brake its acceleration.

The development of combined by forcespeed motor qualities $[1,3,5,6,7,8$.$] , is one$ of the most important aspects of training and covers all segments. The lack of a superior effort capability can suddenly break the balance shown in the game, decisively influencing individual tactics and implicit collective tactics.

In addressing the methodology of forcespeed development, specialists strive to solve the problem of optimal structuring of the annual training cycle in accordance with the need to ensure a high degree of training. From this context in order to be able to cope with competitive efforts a number of specialists consider primarily the force-speed training [1, $6,7,8]$.

Some specialists consider as an important aspect in terms of knowledge of the implications of this quality (force - speed) in the performance of senior athletes, positive transfer being carried out in a limited group of actions, generally within actions with similar structures in terms of coordination.

The force-speed ratio is a transfer inversely proportional to the degree of physical preparation, the maximum frequency of movements is determined at the joints, the movements being performed with maximum amplitude but also resistance, within a certain time interval.

T.Bompa [2]; V.N. Platonov [6], considers that the explosion (detachment) will be greater if a greater number of neuromuscular formations are to be included in the contraction; it can be very large if they achieve a very rapid contraction, both aspects being perfectible through the training process.

Specialists in sports training theory are still looking for new methodologies for the efficiency of combined motor quality "force- 
speed", in this respect they present the advantages and limits of the use of cardiorespiratory, metabolic and hormonal parameters for the control of training lessons, the structure and principles of long-term training of athletes in the Olympic sports system, the complexity and speed of the actions specific to the game of rugby is given not only by the special motor qualities of the athlete, but also by a background of general and motor intelligence.

According to some authors $[1,2,5,6,8$.], the ability of force-speed holds a very important role in achieving performance in a number of sports branches and events based on acyclic movements such as: throwing, jumping, sports games, in which the results depend on the force of impulse, it is the quality of the muscular system to overcome a sufficiently high resistance through a maximum contraction speed.

The development of the (explosive) impulse force has favourable effects on the length of the steps and their frequency. If the impulse in the supporting phase is greater, then increases the length of the step and shorten the supporting time causing the significant increase in tempo.

So, maximum force largely determines explosive force, but also another type of force, called by some starter authors, which in turn influences detente. According to some authors $[1,2,3,6$.$] , the force in speed is the quality of$ the neuromuscular system to perform rapid movements under the conditions of defeating a resistance (relatively average).

The starting force is the ability to achieve maximum force at the beginning of movement (at the onset of muscle contraction) with the effect of achieving a high initial speed (synonymous with acceleration speed at speed running).

The initial force is determined by the degree of force in the initial part, the faster the first part, the more the muscle has the ability to react quickly in the development of the force. Interestingly, we find that the initial strength of the muscles is constant and even if followed by an explosive gesture, it remains almost independent of the athlete's emotional state.

The force-speed capacity is defined as the ability of some muscle groups to develop maximum strength in as short a time as possible, it is the anabiorose capacity. The effort is a request to the body and obliges it to draw up a response, which is, on the one hand, a requested effort and, on the other hand, a labour performed.

Regarding the place of work for the development of speed and strength in the case of the training lesson, a group of specialists [1, $3,4,5,6$.] mentions, as the most appropriate sequence would be the following: exercises for learning the technique and its improvement, exercises for the development of speed and skill, exercises for the development of force and exercises for the development of resistance.

D.Badea [2, p. 123] claims that in sports games it is spoken of explosive force when manifested by movements characterized by its use, important in a very short time, limited by the following exercise. The first phase characterizes the ability of the muscles to develop instant and explosive force.

Thus, addressing the problem with the analysis of the combined quality of forcespeed allows us to highlight the following:

- it should be taken into account that when a motor quality develops, in a given task, a single capacity is not improved, in order to avoid competing skills, interference (combination of phenomena) and therefore to avoid negative transfer (negative influence), it is advisable not to plan lesson themes whose means have the same share of development;

- the provision of explosive force is closely linked to the anaerobic power capacities of the muscles concerned;

- the actuators aim both at the appropriation of the moving elements which make up the technical process and for the development of the combined motor qualities concerned; 
- simultaneous development of speed, strength and skill for choosing the best moment to hit the ball and to perform jumping, change of direction in running, etc.;

- when we propose working with weights to select the means of working in such a way that eccentric muscle contractions are quickly followed by concentric contractions.

On a deeper analysis, the importance of developing the ability of force-speed is deduced, as a necessity to respond to the game under pressure that becomes more aggressive and in this context intervenes the power of the player to physically resist and stressors throughout the game.

\section{Conclusions}

- Analyzing the opinions of specialists on the training of performance rugby players through the differentiated development of force-speed qualities, a number of problems are highlighted, which determine the importance and role of applying new methodologies to optimize the sports training process at the highest level.

- The opinions of the specialists were unequivocal on the importance of the development of the force-speed capabilities of the performance rugby players and beyond, this being one of the dominant motor qualities in players of this level.

- Therefore, the problem proposed for research is a fairly current one and can be extrapolated to other sports games, being a rather important methodological support for specialists in the field.

\section{References:}

1. Bompa T. (2001). Periodizarea - Teoria şi metodologia antrenamentului, ediţia a II-a. Bucureşti: Editura Ex-Ponto. 276 p.

2. Bragarenco N. (2017). Dezvoltarea capacităţilor coordinative: monografie. Chişinău: „Valinex” SRL. 120 p.

3. Ciorbă C. şi col. (2007). Jocuri sportive, curs de bază. Chişinău: „Valinex” SRL, p. 101-132.

4. Dragnea A. (2000). Teoria educației fizice și sportului. București: Editura Cartea Școlii. 241 p.

5. Platonov N.V. (1984). Teoria antrenamentului sportiv. Moscova, p.30-60.

6. Rață G., Carp I. (2013). Principii și metode didactice specifice educației fizice și sportului. Bacău: Ed. „Alma Mater”. 176 p.

7. Triboi V., Păcuraru A. (2013). Teoria şi metodologia antrenamentului sportiv. Iaşi: Ed. „PIM”. $374 \mathrm{p}$. 